\title{
Slowly progressive apraxia in Alzheimer's disease
}

\author{
R C Green, F C Goldstein, S S Mirra, N P Alazraki, J L Baxt, R A E Bakay
}

\begin{abstract}
Slowly progressive apraxia due to Alzheimer's disease was encountered in a 66 year old, right handed man whose initial impairments included coordinated movements of the left hand and some features of the alien hand syndrome. Over four years, the patient developed progressively worsening deficits of memory and language. A biopsy of his right temporal lobe showed numerous plaques and neurofibrillary tangles. Pronounced right parietal lobe hypoperfusion on serial SPECT suggests involvement of this region in contralateral praxis.
\end{abstract}

(F Neurol Neurosurg Psychiatry 1995;59:312-315)

Keywords: Alzheimer's disease; subtypes; apraxia; movements

Apraxia is a syndrome of impaired execution of learned skilled movements that cannot be explained by weakness, incoordination, sensory loss, lack of comprehension, or inattention. Apraxia is common in Alzheimer's disease, usually appearing after impairments of memory and language are established. A few cases of slowly progressive apraxia without deficits in memory and language have been described but the underlying pathology was not established. ${ }^{1-4}$ Our patient showed progressive apraxic symptoms early in the course of his illness.

\section{Patient history}

A 66 year old, right handed, college educated chemical engineer experienced the insidious onset of finger and hand incoordination in association with complex movements of the left hand at the age of 60 . Initially, he had minor problems driving his car and shuffling playing cards, but by the end of 1988 he had stopped working and could not easily tie his shoelaces, button his shirt, or eat with his left hand. He and his family denied any language or memory difficulties. When initially examined in June 1990 the patient was aware of his deficits, stating that his left hand "seems to have a life of its own." His wife confirmed extraneous behaviours reminiscent of alien hand syndromes, such as placing a napkin in his lap with his right hand, only to have his left hand reach out and remove it. After six months, he had problems performing mental arithmetic, writing script or numbers with his right hand, and he experienced spatial confusion when driving or in a familiar environment without visual cues. $\mathrm{He}$ and his wife agreed that he still did not have problems with gait, word finding, comprehension, or memory. There was no personal or family history of neuropsychiatric problems or substance misuse, except for a maternal aunt clinically diagnosed as having Alzheimer's disease. Detailed neurological examination was normal, including motor tone and primary sensory and motor function in the limbs, except for moderately severe agraphaesthesia and astereognosis in the left hand and difficulties with left hand praxis.

Neuropsychological evaluations were conducted in July 1990, January 1991, and July 1992 (table). Apraxia was evaluated by having the patient carry out gestures and imagined use of objects. When seen in July 1990, imitation was performed poorly by each hand and the execution of transitive and intransitive movements to command was worse with the left hand. Responses were slow, and body part as the object and spatial displacements were common. Performance did not appreciably improve when the patient was tested with actual objects. At his six month follow up, there was a noticeable deterioration of transitive and intransitive movements with the right hand. Imitation was still poor bilaterally, and had become even worse with the left hand. By July 1992 he could only perform simple right handed movement to command and imitation, and he could not execute any movements with his left hand.

In July 1990 he could not determine how to hold a pencil with his left hand and he could not write a sentence correctly to dictation with his right hand, although he could copy. By January 1991, his writing with his right hand both to dictation and from copy deteriorated and by July 1992 he was unable to write his name. His drawings were tremulous and micrographic, and he was impaired in copying simple geometric designs on the Benton visual retention test. By contrast with his dyspraxic and dysgraphic symptoms, his language abilities were relatively preserved in July 1990 and January 1991. By July 1992, however, he displayed severe dysnomia, with many perceptual misidentifications and semantic paraphasias. Generation of words 
Neuropsychological test results

\begin{tabular}{|c|c|c|c|}
\hline & Fuly 1990 & fanuary 1991 & Fuly 1992 \\
\hline \multicolumn{4}{|l|}{$\begin{array}{l}\text { Intellectual functioning: } \\
\text { (WAIS-R: } \text { mean }=100, \mathrm{SD}=15 \text { ) }\end{array}$} \\
\hline Verbal IQ & 109 & 110 & 69 \\
\hline Performance IQ & 63 & 60 & 60 \\
\hline Full Scale IQ & 88 & 87 & 63 \\
\hline \multicolumn{4}{|l|}{$\begin{array}{l}\text { Verbal age scaled scores: } \\
(\text { mean }=10, \mathrm{SD}=3)\end{array}$} \\
\hline Information & 14 & 14 & 1 \\
\hline Digit span & 8 & 5 & 3 \\
\hline Vocabulary & 14 & 14 & 11 \\
\hline Arithmetic & 4 & 4 & 2 \\
\hline Comprehension & 12 & 16 & 8 \\
\hline Similarities & 16 & 16 & 3 \\
\hline \multicolumn{4}{|l|}{ Performance age scaled scores: } \\
\hline Picture completion & 3 & 4 & 2 \\
\hline Picture arrangement & 6 & 2 & 2 \\
\hline Block design & 2 & 2 & 3 \\
\hline Digit symbol & 2 & 1 & 1 \\
\hline \multicolumn{4}{|l|}{ Language: } \\
\hline \multirow{2}{*}{\multicolumn{4}{|c|}{$\begin{array}{l}\text { Apraxia (No correct) } \\
\text { Limb intransitive }(12 \text { total): }\end{array}$}} \\
\hline Limb intransitive (12 total): & & & \\
\hline $\mathrm{RH}$ : commands & 8 & 6 & 1 \\
\hline Imitation & 9 & 9 & 0 \\
\hline LH: commands & 2 & 3 & 0 \\
\hline Imitation & 8 & 4 & 0 \\
\hline \multicolumn{4}{|l|}{ Limb transitive ( 7 total): } \\
\hline RH: commands & 5 & 2 & 0 \\
\hline Imitation & 4 & 3 & 0 \\
\hline LH: commands & 2 & 2 & 0 \\
\hline imitation & 6 & 4 & 0 \\
\hline \multicolumn{4}{|l|}{ Writing (No correct/6 words) } \\
\hline Dictation (RH, LH) & 2, CND & 3, CND & CND, CND \\
\hline Copy $(\mathrm{RH}, \mathrm{LH})$ & 6, CND & 4, CND & CND, CND \\
\hline Naming (No correct/60 pictures) & 55 & 55 & 10 \\
\hline \multicolumn{4}{|l|}{ Verbal fluency (No correct) } \\
\hline Three letters & 26 & 20 & 0 \\
\hline Three categories & 46 & 33 & 9 \\
\hline \multicolumn{4}{|l|}{ Tactile naming ( 14 objects) } \\
\hline RH (No correct) & 12 & 10 & NG \\
\hline LH (No correct) & 8 & 10 & NG \\
\hline \multicolumn{4}{|l|}{ Memory: } \\
\hline \multicolumn{4}{|l|}{ Picture recognition } \\
\hline (No correct/100) & 78 & 67 & CND \\
\hline \multicolumn{3}{|l|}{ Story recall } & 0 \\
\hline \multirow{2}{*}{$\begin{array}{l}\text { Story recognition } \\
\text { (No units } / 20)\end{array}$} & & & \\
\hline & 14 & 13 & $6 / 13$ \\
\hline
\end{tabular}

$\mathrm{CND}=$ could not do; $\mathrm{NG}=$ not given $; \mathrm{LH}=$ left hand; $\mathrm{RH}=$ right hand .

beginning with specific letters was in the low to normal range at his initial session, and deteriorated further in subsequent examinations.

When initially tested, the patient's visual recognition memory was in the low average range. Six months later, there was a noticeable decline, and by July 1992 he could not perform the task. Over the two years he was followed up he exhibited a steady decline in his verbal intellectual abilities. The table shows a pronounced difference between his average verbal IQ and severely impaired performance IQ in July 1990 and January 1991. By July 1992 the verbal IQ had dropped 40 points, and he had lost the insight that had characterised his earlier testing sessions.

Diagnostic testing in the summer of 1990 and the winter of 1991 included 1.5 Tesla MRI showing only generalised atrophy, a moderately abnormal EEG, with diffuse background slowing, and normal routine laboratory studies including thyroid function tests, vitamin B12 concentration, and sedimentation rate. A lumbar puncture showed normal opening pressure, acellular fluid with a normal glucose concentration, and a slightly raised protein of $54 \mathrm{mg} / \mathrm{dl}$. SPECT was performed 20 minutes after intravenous injection of $20 \mathrm{mCi}$ technetium-99 m hexamethyl- propyline amineoxime with the patient supine in a low stimulation environment in August 1990 and February 1991. These studies showed hypoperfusion in the right frontal, parietal, temporal, and occipital regions (fig 1).

In February 1991, biopsies of the middle and inferior temporal cortices on the right side were performed. Neuropathological examination with Bielschowsky silver staining of the paraffin embedded material showed numerous senile plaques (up to 50 per low power field) (fig 2). The plaques were predominantly neuritic in nature, some containing amyloid cores; a few diffuse plaques were also seen. The density of neuritic plaques met conventional neuropathological criteria for diagnosis of Alzheimer's disease. ${ }^{5}$ Numerous neurofibrillary tangles were also noted, particularly in the deeper layers of cortex, along with neuropil threads.

\section{Discussion}

Apraxia is common in dementia, occurring in Huntington's disease, corticobasal ganglionic degeneration, and occasionally in Parkinson's disease. Apraxia is also common in Alzheimer's disease, but is rarely described as a presenting symptom. Three cases of slowly progressive apraxia without tissue diagnoses have been reported, but two of these seemed to represent visual agnosias in which the patients made errors imitating gestures but performed correctly to command. ${ }^{6}$ The third case, a patient with an insidious loss of abilities to perform limb and axial movements to both imitation and command, more closely resembles our patient, but there was no follow up or tissue diagnosis.

Patients with Alzheimer's disease established by biopsy have presented with progressive left sided clumsiness, astereognosis, agraphaesthesia, and choreoathetoid movements $^{7}$ as well as with alien left hand and myclonus. ${ }^{8}$ Several other recent clinical case reports of slowly progressive apraxia have been associated with unilateral or bilateral cortical atrophy and diminished SPECT activity in parietal regions $\mathrm{s}^{1-4}$ but none of these reports included a tissue diagnosis. Published reports of SPECT findings in patients with Alzheimer's disease indicate that parietal lobe hypoperfusion is often seen, but it usually presents bilaterally. Unilateral apraxia has often been described in patients with focal lesions, particularly strokes, but is also unusual in Alzheimer's disease.

Apraxia of the non-dominant limb may be a result of interhemispheric disconnection associated with lesions of the corpus callosum fibres, ${ }^{9}$ and is often, but not exclusively, associated with left hemispheric lesions and with aphasia. ${ }^{10-12}$ Although it is less frequent, apraxia can also occur after right hemispheric lesions, ${ }^{11}{ }^{13-19}$ raising the possibility that the visuokinaesthetic engrams containing spatial and temporal representations of learned movements may occasionally be represented either bilaterally or in the non-dominant 
Figure 1 SPECT axial (above), sagittal (lower left) and coronal (lower right) slices of technetium99 m HMPAO brain perfusion scans from February 1991 show deficient cerebral perfusion in the right cerebral cortex in all projections (arrows), most severe in the posterior parietal cortex. Perfusion on the left is normal.

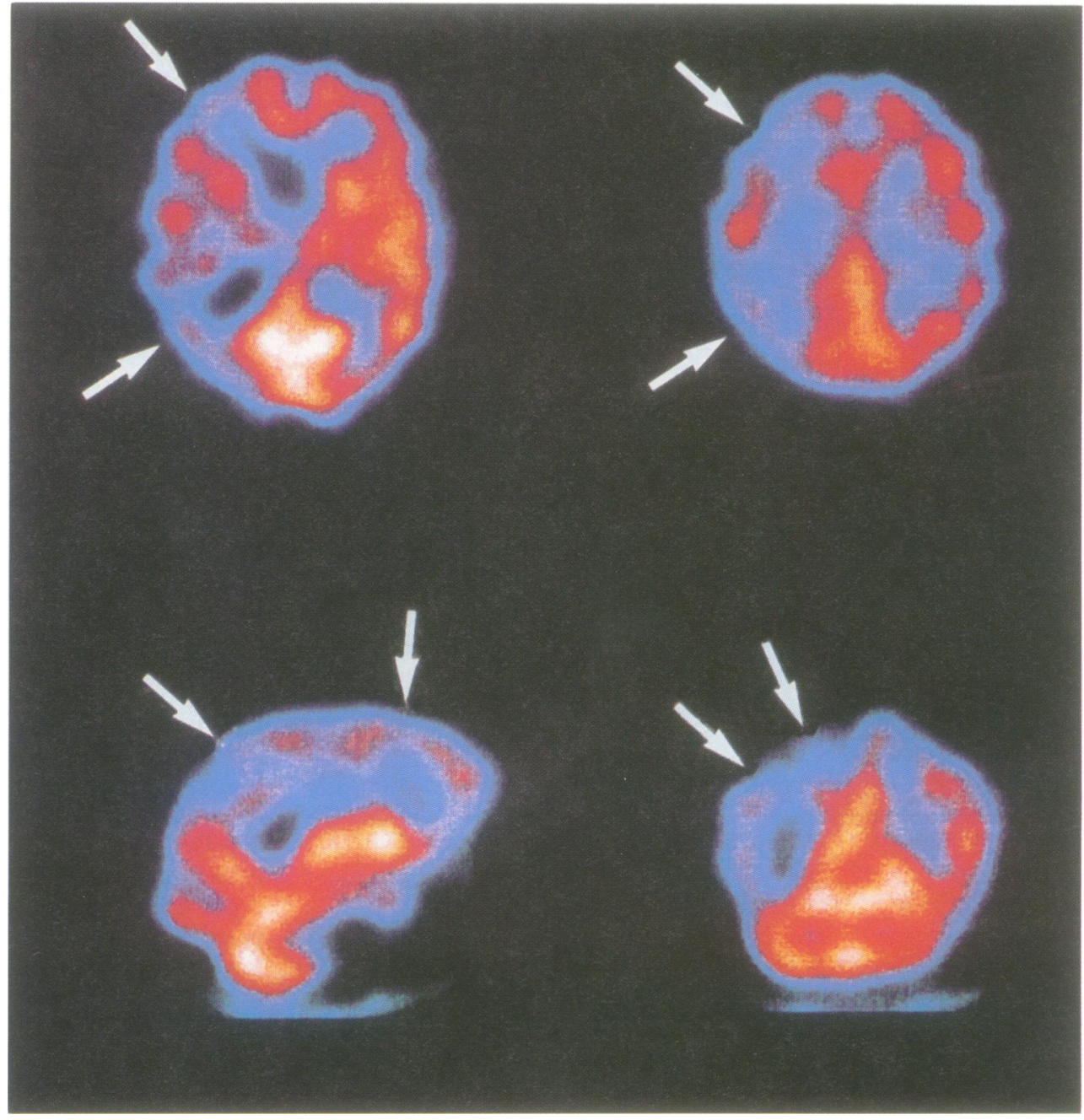

hemisphere, and not only in the left hemisphere. ${ }^{20-24}$

There is no way of knowing the full extent of neuropathology in a living patient with neurodegenerative disease. It is of interest, however, that this patient presented with prominent symptoms of the left hand and that SPECT perfusion images and quantitative analysis showed mild frontal and pronounced parietal hypoperfusion in the right hemisphere, supporting the notion that these regions may be salient in contralateral praxis. Indeed, the praxis system in the right hemisphere has been implicated in the mediation of "concrete" or context dependent perfor-

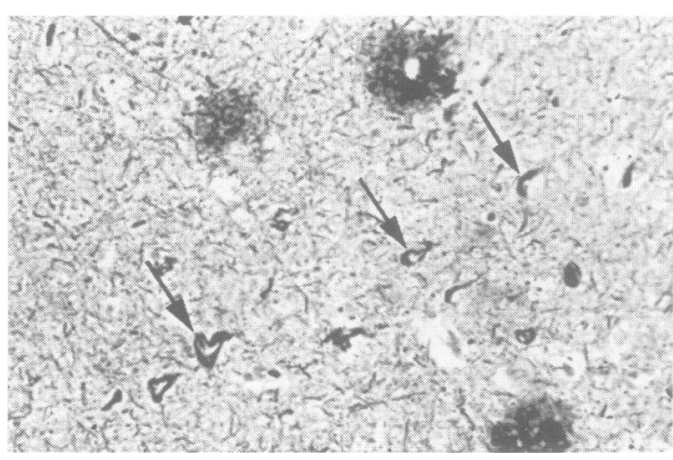

mance of transitive movements and in learning novel movement sequences. ${ }^{25}$ The alien hand features seen in this patient, along with dysgraphia and impaired tactile naming with the left hand, are difficult to explain on the basis of frontal or parietal lesions alone and suggest some degree of interhemispheric disconnection early in the disease process.

This work was presented in part to the International This work was presented in part to the International Neuropsychological Society, San Diego, CA, 1992. It was supported by the Emory Research Grant Committee, a grant from the Fraternal Order of Eagles, and NIA grants P30AG10130 (Emory

1 Dick JP, Snowden JS, Northen B, Goulding PJ. Slowly progressive apraxia. Behavioural Neurology 1989;2:

2 Rapcsak SZ, Ochipa C, Roeltgen MG, Roeltgen DP. Posterior cortical atrophy: neuropsychological and neuoradiological correlates. Ann Neurol 1990;28.255.

3 Okuda B, Tachibana H, Kawabata K, Takeda M, Sugita $M$. Slowly progressive limb-kinetic apraxia with a decrease in unilateral cerebral blood flow. Acta Neurol Scand 1992;86:76-81

4 Azouvi P, Bergego C, Robel L, Marlier N, Durand I, Held JP, Bussel B. Slowly progressive apraxia: two case studies. F Neurol 1993;240:347-50.

5 Khachaturian ZS. Diagnosis of Alzheimer's disease. Arch

6 De Renzi E. Slowly progressive visual agnosia or apraxia without dementia. Cortex 1986;22:171-80.

7 Crystal HA, Horoupian DS, Katzman R, Jotkowitz S. Biopsy-proved Alzheimer disease presenting as a right parietal lobe syndrome. Ann Neurol 1982;12:186-8. Neurol 1985;42:1097-105. 
8 Ball JA, Lantos PL, Jackson M, Marsden CD, Scadding JW, Rossor MN. Alien hand sign in association with Alzheimer's histopathology. $\mathcal{f}$ Neurol Neurosurg Plzheimer's histopathology.

9 Geschwind N, Kaplan E. A human cerebral deconnection syndrome: a preliminary report. Neurology 1962;12: 675-85.

10 De Renzi E, Faglioni P, Sorgato P. Modality-specific and supramodal mechanisms of apraxia. Brain 1982;105: 301-12.

11 Kertesz A, Ferro JM, Shewan CM. Apraxia and aphasia: the functional-anatomical basis for their dissociation. Neurology 1984;34:40-7.

12 Papagno C, Sala SD, Basso A. Ideomotor apraxia without aphasia and aphasia without apraxia: the anatomical support for a double dissociation. 7 Neurol Neurosurg Psychiatry 1993;56:286-9.

13 Pieczuro A, Vignolo LA. Studio sperimentale sulla aprassia ideomotoria. Sistema Nervoso 1967;19:131-43.

14 De Renzi E, Pieczuro A, Vignolo LA. Ideational apraxia: a quantitative study. Neuropsychologia 1968;6:41-52.

15 Assal G, Perentes E, Deruaz J-P. Crossed aphasia in a right-handed patient-postmortem findings. Arch Neurol 1981;38:455-8.

16 Basso A, Capitani E, Laiacona M, Zanobio ME. Crossed aphasia: one or more syndromes? Cortex 1985;21:25-45.
17 De Renzi E, Motti F, Nichelli P. Imitating gestures-A quantitative approach to ideomotor apraxia. Arch Neurol $1980 ; 37: 6-10$.

18 Haaland $\mathrm{KY}$, Flaherty D. The different types of limb apraxia errors made by patients with left vs right hemiapraxia errors made by patients with left vs

19 Rapcsak SZ, Gonzalez Rothi LJ, Heilman KM. Apraxia in a patient with atypical cerebral dominance. Brain Cogn 1987;6:450-63.

20 Ajuriaguerra J, Muller M, Tissot R. A propos de quelques problemes poses par l'apraxie dans les demences. Encephale 1960;49:375-401.

21 Goodglass H, Kaplan E. Disturbance of gesture and pantomime in aphasia. Brain 1963;86:703-20.

22 Kimura D. Neuromotor mechanisms in the evolution of human communication. In: Steklis $\mathbf{H}$, Raleigh $\mathbf{M}$, eds. Neurobiology of social communication in primates: an evolutionary perspective. New York: Academic Press, 1979. $197-219$.

23 Heilman KM Apraxia. In: Heilman K, Valenstein E, eds. Clinical neuropsychology. New York: Oxford University Clinical neuropsychology

24 Heilman KM, Rothi LJ, Valenstein E. Two forms of ideomotor apraxia. Neurology 1982;32:342-6.

25 Rapcsak SZ, Ochipa C, Beeson PM, Rubens AB. Praxis and the right hemisphere. Brain Cogn 1993;23:181-202.

\section{NEUROLOGICAL STAMP}

\section{Chaulmoogra (Hydnocarpus wightiana)}

The seeds of the fruit of the chaulmoogra tree contain strongly antibacterial chemicals, two of which, hydnocarpic and chaulmoogric acids, destroy the bacterium Myobacterium leprae. Ancient Hindu and Chinese documents described an oil that was effective against leprosy, and it is likely that this came from the chaulmoogra tree. Only about the middle of the last century was the oil taken seriously by western physicians. It was investigated, tested, and soon imported from China but the supply was severely limited. In some places today, the ingredients of chaulmoogra oil, modified by chemists, are still used to cure early cases of leprosy, but advanced cases do not yield to the treatment.

The chaulmoogra tree is shown on a stamp issued by Fiji in 1970 (Stanley Gibbons 420, Scott 289).

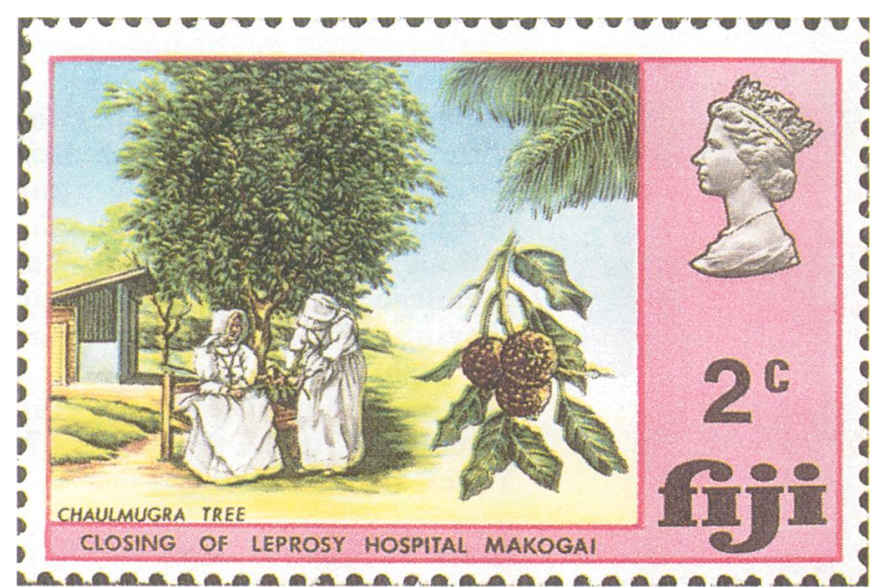

L F HAAS 